\title{
Retrospective Evaluation of the First 150 Patients with Vascular Surgery in A New Cardiovascular Surgery Clinic
}

\author{
Mazlum Şahin ${ }^{1}$, Fatma Tuğba İlal Mert ${ }^{1}$, Gökay Altaylı ${ }^{1}$
}

${ }^{1)}$ Haseki Education and Research Hospital, Cardiovascular Surgery Department, Specialist Dr., Istanbul, Turkey

\begin{abstract}
Objective: This study aimed to retrospectively evaluate the data of patients undergoing peripheral arterial vascular surgeries and to present our approach to peripheral arterial disease (PAD) in our clinic, which was put into service as of September 2014.
\end{abstract}

Methods: Data on 151 patients undergoing peripheral arterial vascular surgery between September 2014-December 2016 were retrospectively evaluated. Of the patients, $45(29.80 \%)$ underwent emergency surgery and $106(70.19 \%)$ underwent elective surgery. Of emergency surgeries, 31 (68.88\%) patients had acute embolism. Among elective surgeries, femoropopliteal bypass was the most common procedure in 52 patients. While above-knee femoropopliteal bypass was performed in $40(76.92 \%)$ patients, vena saphena magna (VSM) could be used as a graft in 31 patients. VSM could be used in 9 of 12 patients undergoing below-knee femoropopliteal bypass.

Results: Of 151 patients, 14 (9.27\%) were admitted for revision during the postoperative period. Among 52 patients undergoing femoropopliteal bypass, 7 were re-operated (4 underwent above-knee and 3 underwent below-knee femoropopliteal bypass). While the polytetrafluoroethylene graft was used in all of these patients, none of the patients with VSM graft required revision. The patient with Shamblin type-III tumor, who was operated due to glomus caroticum, developed graft occlusion and was re-operated; however, hemiplegia was developed postoperatively. Mortality occurred in 4 patients ( 2 with abdominal aortic aneurysm rupture and 2 with penetrating injury). All of them had hypovolemic shock prior to the surgery.

Conclusion: There is a need for an experienced team for PAD and the treatment method to be applied should be patient-based.

Keywords: Peripheral arterial disease, vascular surgery, morbidity, mortality 


\section{Introduction}

Peripheral arterial disease (PAD) due to atherosclerosis is a significant cause of morbidity and mortality. PAD is an important health problem with a gradually increasing prevalence. It has been estimated that more than 30 million people worldwide are affected by PAD. The frequency of PAD over the age of 65 years has been reported to be $17 \%$ among females and $20 \%$ among males. According to the non-invasive criteria, while the prevalence of PAD is 3\%-7\% under the age of 60 years, it reaches to $20 \%$ in the population aged over 70 years. Additionally, one-third of these people are asymptomatic. ${ }^{(1)}$ The treatment of PAD may be medical, endovascular or surgical. In the present study, we aimed to retrospectively evaluate the data of patients undergoing PAD surgeries and to present our approach to PAD in our clinic, which was put into service as of September 2014.

\section{Methods}

Data on patients undergoing PAD surgery between September 2014 and December 2016 in our clinic were retrospectively evaluated. The study was approved by the Ethics Committee of Training and Research Hospital and informed consents of patients were obtained. Absence of distal pulses detectable by palpation or by a hand-held Doppler was considered adequate for the diagnosis of PAD. In addition to the clinical and physical examination, patients also underwent vascular Doppler ultrasonography. While patients who were admitted with acute arterial embolism were operated based on the Doppler ultrasonography findings, computed tomography angiography and/or conventional angiography was used as the diagnostic method in the patients with PAD. Conventional angiography was performed in patients for whom endovascular surgery was planned or who required coronary angiography. Among the 31 patients who underwent concurrent coronary angiography, 13 had coronary lesion and coronary artery bypass graft $(\mathrm{CABG})$ surgery was primarily performed in 8 of these patients.

\section{Surgical Strategy and Techniques}

\section{Femoropopliteal Bypass}

Patients underwent venous Doppler ultrasonography prior to the surgery. The wall structure and the di- ameter of the vena saphena magna (VSM) were examined. Polytetrafluoroethylene (PTFE) grafts were used when the VSM had a diameter of $<3 \mathrm{~mm}$ or with packet formation, or had fibrotic valves. VSM was excised segmentally by intermittent skin incision in patients for whom VSM could be used and a reverse bypass was performed.

\section{Glomus Caroticum (GC)}

Two patients were operated due to GC; one with Shamblin type II tumor and the other with Shamblin type III tumor. In the patient with Shamblin type II tumor, the tumor was removed preserving the integrity of carotid artery. In the patient with Shamblin type III tumor, the tumor was removed together with the external carotid artery and the internal carotid artery and PTFE graft was used to maintain the continuity of internal carotid artery .

\section{Carotid-to-Subclavian Bypass}

A left supraclavicular transverse incision extending lateral to the clavicular head of the sternocleidomastoid muscle was performed. This provides excellent exposure for both carotid artery and subclavian artery. The subclavian artery was exposed by dividing the inferior insertion of the anterior scalene muscle (on the first rib). We took care to identify and protect the phrenic nerve. We ligated the thoracic duct and all its tributaries. We performed the carotid-to-subclavian bypass with $6 \mathrm{~mm}$ ringed PTFE graft. Carotid-to-subclavian bypass was performed concurrently with thoracic endovascular aneurysm repair in 2 patients with type III dissection involving the left subclavian artery.

\section{Popliteal Artery Entrapment Syndrome}

Four patients were operated due to popliteal artery entrapment syndrome; 2 with type I and 2 with type II. Popliteal artery was approached posteriorly using $\mathrm{S}$ incision. Myotomy of the medial head of the gastrocnemius muscle was performed. Despite the relieving of the compression, the vessel wall integrity was not preserved. All patients underwent graft interposition using the saphenous vein.

\section{Statistical Analysis}

Descriptive statistics were expressed as numbers and percentages for categorical variables and as mean 
and standard deviation for numerical variables.

\section{Results}

Of the 151 patients underwent peripheral arterial vascular surgery, 114 were males and 37 were females. The mean age of the patients was $56.5 \pm 13.3$ years (range, $17-78$ years). Of the patients, $37.74 \%$ had a history of smoking. The most prevalent comorbidity was diabetes mellitus followed by coronary artery disease (CAD) and chronic obstructive pulmonary disease (Table 1). Of the 151 patients, $45(29.80 \%)$ underwent emergency surgery and 106 (70.19\%) underwent elective surgery. Of these 45 patients, 31 (68.88\%) presented with a clinical picture of acute embolism and the most common site of occlusion was femoropopliteal region in $21(67.74 \%)$ out of 31 patients. The leading etiological factor was arterial embolus resulted from atrial fibrillation.

Among elective surgeries, the femoropopliteal bypass was the most common procedure performed in 52 patients. While the femoropopliteal bypass was performed above the knee in $40(76.92 \%)$ patients, VSM could be used as a graft in 31 patients. VSM could be used in 9 of 12 patients who underwent below-knee femoropopliteal bypass.

Seventeen patients, who were not suitable for endovascular treatment or required urgent intervention,

Table 1. Demographic and clinical characteristics of the patients

\begin{tabular}{|c|c|}
\hline Characteristics & Data \\
\hline Age, years (mean $\pm S D$ ) & $56.5 \pm 13.3$ \\
\hline \multicolumn{2}{|l|}{ Gender, n (\%) } \\
\hline Female & $37(24.50)$ \\
\hline Male & $114(75.49)$ \\
\hline Smoking, n (\%) & $57(37.74)$ \\
\hline \multicolumn{2}{|l|}{ Comorbidities } \\
\hline Diabetes mellitus, $\mathrm{n}(\%)$ & 32 (21.19) \\
\hline Coronary artery disease, $\mathrm{n}(\%)$ & $22(14.56)$ \\
\hline $\begin{array}{l}\text { Chronic obstructive pulmonary } \\
\text { disease, } \mathrm{n}(\%)\end{array}$ & $9(5.96)$ \\
\hline SD: standard deviation & \\
\hline
\end{tabular}

were operated due to traumatic arteriovenous fistulas (AVFs). Primary repair of the artery and vein after ligation was performed in 2 patients, graft interposition in the artery and primary repair of vein were performed in 5 patients, and graft interposition to the artery and vein was performed in 10 patients. Saphenous vein was used as the graft in all patients (Table 2).

There were 8 patients who were planned to undergo peripheral arterial surgery and had indication for concurrent $\mathrm{CABG}$. In these patients, $\mathrm{CABG}$ was primarily performed since their coronary lesions were serious and the peripheral arterial surgery could be postponed. The left internal mammary artery (LIMA) was not used in 1 patient with Leriche syndrome. Peripheral arterial surgery was performed in the patients in the 1 st month after discharge. Among these patients, 7 underwent femoropopliteal bypass and 1 underwent aortobifemoral bypass. Coronary bypass and carotid endarterectomy were performed in the same session in 6 patients.

After sternotomy, LIMA was prepared and carotid exploration was performed by leaving the LIMA in the chest wall. Carotid endarterectomy was performed following heparinization and the standard CABG was then performed. Of the 151 patients who were operated for peripherial vascular diseases, 14 (9.27\%) were admitted for revision during the postoperative monitoring period. Among these patients, 7 patients underwent

Table 2. Surgical procedures

\begin{tabular}{|l|c|}
\hline Surgery & $\mathbf{n}(\%)$ \\
\hline Femoropopliteal bypass & $52(34.43)$ \\
\hline Embolectomy & $21(13.90)$ \\
\hline Aortobifemoral bypass & $20(13.33)$ \\
\hline Traumatic arteriovenous fistula & $17(11.25)$ \\
\hline Carotid endarterectomy & $13(8.60)$ \\
\hline Femorofemoral bypass & $8(5.29)$ \\
\hline Left aortofemoral bypass & $7(4.63)$ \\
\hline Abdominal aortic aneurysm repair & $5(3.31)$ \\
\hline Popliteal artery entrapment syndrome & $4(2.64)$ \\
\hline Glomus caroticum & $2(1.32)$ \\
\hline Caroticosubclavian bypass & $2(1.32)$ \\
\hline
\end{tabular}


femoropopliteal bypass, of whom 4 underwent aboveknee femoropopliteal bypass and 3 underwent belowknee femoropopliteal bypass. While the PTFE graft was used in all of these patients, none of the patients with VSM graft required revision. During the revision, graft embolectomy was performed in 2 patients and distal anastomosis was re-performed in 5 patients, in which the Miller cuff was used. While the earliest revision was required in the 7 th month in 1 patient who underwent below-knee femoropopliteal bypass using the PTFE graft, the average time for revision was 12 months (mean, $12 \pm 4.5$ months). Two-year patency rate was $75 \%$ in the patients undergoing below-knee femoropopliteal bypass and $90 \%$ in the patients undergoing above-knee femoropopliteal bypass.

Femoral wound site revision was performed in 4 patients due to tissue infection. Of these patients, 3 underwent femoropopliteal bypass and 1 underwent aortobifemoral bypass. None of the patients developed graft infection. In 1 one patient who underwent femoropopliteal bypass, an early revision was performed due to postoperative bleeding.

One patient who underwent revision presented to our clinic 4 days after the onset of symptoms. The graft patency was achieved after embolectomy; however, the below-knee amputation had to be performed. The patient, who was operated due to GC and surgically classified as the Shamblin type-III tumor, developed graft occlusion and hemiplegia was occurred (Table 3).

Mortality occurred only in 4 patients, of whom 2 were diagnosed as abdominal aortic aneurysm rupture and 2 had penetrating injury. All of these patients had hypovolemic shock prior to the surgery.

\section{Discussion}

The main principles of vascular surgical approaches were first defined by Carrel a century ago. ${ }^{(2,3)}$ After the experiences on the vascular injury gained during the World War I and II, rapid deceleration has been provided in the incidence of amputations following reconstructive vascular interventions.

Peripheral artery disease is encountered in $13 \%$ of the people aged over 50 years. The frequency of symptomatic PAD in the Western populations has been reported to be $5 \%$ in the $55-74$ age group. ${ }^{(4)}$

Peripheral artery disease is considered as a predictor for CAD. In the study by Poredos and Jug, ${ }^{(5)}$ symptomatic atherosclerosis was reported in $821(86.2 \%)$ of 952 subjects, who were at high risk for cardiovascular disease and the asymptomatic patients had at least two risk factors. Moreover, PAD was detected in $42 \%$ of the patients with CAD and there was no significant difference between the CAD and PAD groups in terms of the risk profiles. ${ }^{(5)}$ In the present study, the patients who underwent elective surgeries were evaluated for cardiac diseases and coronary angiography was performed, when required. $\mathrm{CABG}$ was primarily performed in 8 of these patients.

In the Guideline for the Treatment of Peripheral Artery and Vein Diseases published in 2008 by the Turkish Society of Cardiovascular Surgery, aortoiliac and femoropopliteal lesions were classified from simple to complex using the Trans-Atlantic Inter-Society Consensus (TASC) Classification System as TASC A, B, C,

Table 3. Morbidity

\begin{tabular}{|l|l|r|}
\hline Morbidity & \multicolumn{1}{|c}{ Surgery } & $\mathbf{n}(\%)$ \\
\hline \multirow{2}{*}{ Graft occlusion } & Above-knee femoropopliteal bypass & $4(10)$ \\
\cline { 2 - 3 } & Below-knee femoropopliteal bypass & $3(25)$ \\
\hline \multirow{2}{*}{ Wound-site infection } & Femoropopliteal bypass & $3(5.76)$ \\
\hline Bleeding revision & Aortobifemoral bypass & $1(5)$ \\
\hline Cerebrovascular accident & Femoropoplitealbypass & $1(0.72)$ \\
\hline Extremity loss & Glomus caroticum & $1(50)$ \\
\hline
\end{tabular}


and $\mathrm{D}$ and in general, endovascular treatment was recommended for type A and B lesions and open surgery was recommended for type $\mathrm{C}$ and $\mathrm{D} .{ }^{(6)}$

An update summarizing the literature on endovascular and open surgery procedures but not including definite recommendations was published in 2015. ${ }^{(7)} \mathrm{In}$ this update, definite treatment recommendations were not included as was in the TASC II. The main reason of this might be the facts that comparative studies have not been adequate in quality and in number to support the "endovascular approach at first" and that no consensus could have been provided. In this update, the common point is that life style changes, drug therapies, and exercises prior to the invasive procedure are still valid.

In the present study, the treatment modalities were identified based on age, occupation, and range of claudication. Medical therapy was preferred in the patients with long-distance claudication, advanced-age, and concomitant cardiac and pulmonary problems and in the inactive patients. The indication for invasive procedure was determined based on clinical picture of the patients and using the Fontaine classification.

Invasive procedure was planned, if a young patient with active life style had serious claudication and could not eliminate this problem by changing his/her life style, or if resting pain could not be relieved by conservative methods, or if refractory ulcer was present. Surgery, as a treatment method, was considered in the young patient group without high-risk for surgery. The remaining patient group was discussed in the cardiology clinic in the case-discussion meeting organized weekly. Endovascular treatment was performed in the patients considered appropriate.

Among graft materials, autologous vein grafts are still the most popular in femoropopliteal bypass. ${ }^{(8,9)}$ For this reason, VSM should be considered as the optimal graft material. Autologous veins remain vital for a long time after implantation, are not rejected, and continue to be nourished by diffusion. However, endothelial damage may occur while preparing autologous vein grafts; this endothelial damage likely to occur during surgery is the most important factor influencing the graft patency. ${ }^{(8-10)}$ Other factors that influence the patency of VSM include wall structure, diameter $(>3.5 \mathrm{~mm})$, and presence of varices and fibrotic valves. ${ }^{(1)}$ In the pre- sent study, the diameter and wall structure of the VSM were evaluated by the venous Doppler ultrasonography. VSM was excised segmentally by intermittent incisions in all patients with the vein suitable for using as graft.

It is emphasized that while the primary goal of the treatment of a patient with acute arterial thromboembolic occlusion is to keep patient alive, the second goal is to enable the vitality of extremity. ${ }^{(12)}$ In patients diagnosed with arterial embolism, arterial embolectomy is the first choice of treatment method. The study by Taviloğlu et al. ${ }^{(13)}$ reported the amputation rate after embolectomy as $2.1 \%$ and mortality rate as $12.5 \%$ for the interventions performed within the first 12 hours, whereas these rates were found to be $39.2 \%$ and $37.7 \%$, respectively for the interventions performed after the 12 th hour. In the present study, intervention was performed after 12 hours in 3 of 21 patients who underwent embolectomy. Mortality or amputation was not encountered in none of the patients.

Traumatic AVFs may usually occur due to penetrating injuries or fractures of the regions where the artery and vein exist together or closely. More than $50 \%$ of traumatic AVFs are seen in the lower extremities. It is encountered in the femoral artery by $29 \%$ and in the popliteal artery by $16 \%{ }^{(14)}$ In the present study, AVFs developed in the lower extremities of 16 of 17 patients. Treatment options for traumatic AVFs include surgical and endovascular (graft-coated stent or coil embolization) approaches. The advantages of endovascular treatment are lower complication rate as compared with surgical treatment and being non-invasive.

Patients undergoing endovascular treatment are usually discharged within a day; thus, hospital cost and workforce loss are minimized. In addition, intervention site is small and blood loss is minimum. ${ }^{(15)}$ In the present study, endovascular treatment was primarily preferred. Surgery was performed in the patients with hemodynamic instability, endovascular failure, and lesions in the mobile regions.

Primary repair of the artery and vein after ligation was performed in 2 patients, graft interposition in the artery and primary repair of vein were performed in 5 patients, and graft interposition to the artery and vein was performed in 10 patients. Saphenous vein was used as the graft in all patients. 


\section{Conclusion}

Peripheral artery disease is an important problem all over the world as it is quite common in advanced ages, has increasing prevalence, and carries potential

\section{References}

1. Welten GM, Schouten O, Chonchol M, Hoeks SE, Bax JJ, Van Domburg RT, et al. Prognosis of patients with peripheral arterial disease. J Cardiovasc Surg (Torino) 2009;50:109-21.

2. Ceviz M, Yekeler İ, Ateş A, Cerrahoğlu M, Becit N, Dağ Ö. Periferik arter yaralanmalarında cerrahi tedavi: 175 vakanın değerlendirilmesi. Damar Cer Derg 1996;2: 66-72.

3. Solak H, Yeniterzi M, Yüksek T, Eren N, Ceran S, Göktoğan T. Injuries of the peripheral arteries and their surgical treatment. Thorac Cardiovasc Surg 1990; 38: 96-8.

4. Crawford F, Welch K, Andras A, Chappell FM. Ankle brachial index for the diagnosis of lower limb peripheral arterial disease. Cochrane Database Syst Rev 2016;9: CD010680.doi: 10.1002/14651858.CD010680. pub2. [Epub ahead of print]

5. Poredos P, Jug B. The prevalence of peripheral arterial disease in high risk subjects and coronary or cerebrovascular patients. Angiology 2007;58:309-15.

6. Bozkurt AK, Demirkılıç U, Topçuoğlu Ş, Gürbüz A, Yazıcıoğlu L, Küçüker ŞA et al. Türk Kalp Damar Cerrahisi Derneği. Periferik Arter ve Ven Hastalıkları Tedavi Kılavuzu - 2008. Ankara: Öncü Basımevi; 2008 .

7. Jaff MR, White CJ, Hiatt WR, Fowkes GR, Dormandy J, Razavi M, et al. An Update on Methods for Revascularization and Expansion of the TASC Lesion Classification to Include Below-the-Knee Arteries: A Supplement to the Inter-Society Consensus for the Management of Periph- risk factors. In our clinic, 151 arterial vascular surgical procedures were performed with acceptable rates of mortality and morbidity between 2014 and 2016 . eral Arterial Disease (TASC II): The TASC Steering Committee. Ann Vasc Dis 2015; 8: 343-57.

8. Falco E, Celoria G, Nardini A, Saccomanno G, De Franchi G, Zappia F, et al. [Femoro-popliteal bypass with reversed saphenous vein. Experience in a General Surgery Department]. Minerva Chir1995; 50: 883-8.

9. Plecha EJ, Freischlag JA, Seabrook GR, Towne JB. Femoropopliteal bypass revisited: an analysis of 138 cases. Cardiovasc Surg 1996; 4: 195-9.

10. McCollum C, Kenchington G, Alexander C, Franks PJ, Greenhalgh RM.PTFE or HUV for femoro-popliteal bypass: a multi-centre trial. Eur J Vasc Surg 1991;5:435-43.

11. Wilson SE, Veith FJ, Hobson II RW, Williams RA. Vascular surgery principles and practice. New York: McGraw-Hill Book Company; 1987

12. Ranke C, Creutzig A, Alexander K. Duplex scanning of the peripheral arteries: correlation of the peak velocity ratio with angiographic diameter reduction. Ultrasound Med Biol 1992; 18:433-40.

13. Taviloğlu K, Günay K, Asoğlu O, Dilege Ş, Kurtoğlu M. 10 yıllık periferik arteriyel tıkanıklık olgularımızın analizi. Damar Cer Derg1995; 4:17-21.

14. Rich NM, Hobson RW 2nd, Collins GJ Jr. Traumatic arteriovenous fistulas and false aneurysms: a review of 558 lesions. Surgery 1975; 78:81728 .

15. McArthur CS, Marin ML. Endovascular therapy for the treatment of arterial trauma. Mt Sinai J Med 2004;71:4-11.

Received: 08/05/2018

Accepted: 25/05/2018

Published: 01/06/2018

Disclosure and conflicts of interest:

The authors declare no conflict of interest.

\section{Corresponding author:}

Mazlum Şahin

Mail:mzlmshn@gmail.com 